\title{
Protein defects in neuromuscular diseases
}

M. Vainzof and M. Zatz
Centro de Estudos do Genoma Humano, Departamento de Biologia, Instituto de Biociências, Universidade de São Paulo, São Paulo, SP, Brasil

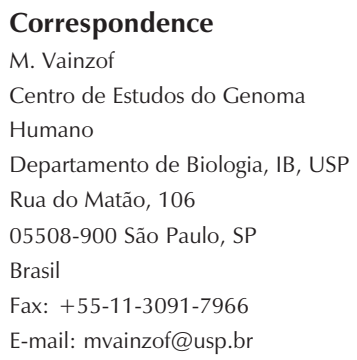

\begin{abstract}
Muscular dystrophies are a heterogeneous group of genetically determined progressive disorders of the muscle with a primary or predominant involvement of the pelvic or shoulder girdle musculature. The clinical course is highly variable, ranging from severe congenital forms with rapid progression to milder forms with later onset and a slower course. In recent years, several proteins from the sarcolemmal muscle membrane (dystrophin, sarcoglycans, dysferlin, caveolin-3), from the extracellular matrix ( $\alpha 2$-laminin, collagen VI), from the sarcomere (telethonin, myotilin, titin, nebulin), from the muscle cytosol (calpain 3, TRIM32), from the nucleus (emerin, lamin A/C, survival motor neuron protein), and from the glycosylation pathway (fukutin, fukutin-related protein) have been identified. Mutations in their respective genes are responsible for different forms of neuromuscular diseases. Protein analysis using Western blotting or immunohistochemistry with specific antibodies is of the utmost importance for the differential diagnosis and elucidation of the physiopathology of each genetic disorder involved. Recent molecular studies have shown clinical inter- and intra-familial variability in several genetic disorders highlighting the importance of other factors in determining phenotypic expression and the role of possible modifying genes and protein interactions. Developmental studies can help elucidate the mechanism of normal muscle formation and thus muscle regeneration. In the last fifteen years, our research has focused on muscle protein expression, localization and possible interactions in patients affected by different forms of muscular dystrophies. The main objective of this review is to summarize the most recent findings in the field and our own contribution.
\end{abstract}

\section{Introduction}

Protein studies are of the utmost importance for enhancing our understanding of genotype/phenotype correlations, as well as for diagnostic purposes, in particular in neuromuscular disorders, in which many genes are involved. Different approaches have been used to study proteins such as detection, quantification and localization by reaction
Key words - Muscular dystrophies

- Muscle proteins

- Dystrophin

- Sarcoglycans with specific antibodies and assays for specific biological activities. Protein studies by analysis of the status of different components of muscle fibers are of the utmost importance for the differential diagnosis and elucidation of the physiopathology of these diseases. This review will focus on the most recent findings in protein analysis and on our own studies of the Brazilian population.

At least 30 different forms of muscular 
dystrophy have been identified to date. lar dystrophies (LGMD) include a heterogeDuchenne (DMD) and Becker (BMD) mus- neous group of progressive disorders mainly cular dystrophies are allelic conditions caused by mutations in the dystrophin gene at Xp21 affecting the pelvic and shoulder girdle musculature, ranging from severe forms with $(1,2)$ (see Table 1). The limb-girdle muscuonset in the first decade of life and rapid

Table 1. Proteins involved in the different genetic neuromuscular diseases.

\begin{tabular}{|c|c|c|c|c|}
\hline Group of proteins & $\begin{array}{l}\text { Proximal muscular } \\
\text { dystrophy phenotypes }\end{array}$ & $\begin{array}{c}\text { Mode of } \\
\text { inheritance }\end{array}$ & $\begin{array}{l}\text { Gene } \\
\text { location }\end{array}$ & MIM \\
\hline \multicolumn{5}{|l|}{ Plasma membrane } \\
\hline Dystrophin & DMD/BMD & $X L$ & Xp21 & 310200 \\
\hline$\alpha$-Sarcoglycan & LGMD2D & AR & $17 q 12$ & 600119 \\
\hline ß-Sarcoglycan & LGMD2E & $A R$ & $4 q 12$ & 604286 \\
\hline$\gamma$-Sarcoglycan & LGMD2C & $A R$ & $13 q 12$ & 253700 \\
\hline$\delta$-Sarcoglycan & LGMD2F & AR & $5 q 33-34$ & 601287 \\
\hline Dysferlin & LGMD2B/Miyoshi myopathy & $A R$ & $2 \mathrm{p} 13$ & 253601 \\
\hline Caveolin-3 & LGMD1C & $A D$ & $3 p 25$ & 601253 \\
\hline \multicolumn{5}{|l|}{ Extracellular matrix } \\
\hline$\alpha 2$-Laminin & Merosin-deficient CMD & $A R$ & $6 q 2$ & 156225 \\
\hline Collagen VI & Ullrich CMD, Bethlem myopathy & AR & $21 q 22$ & 254090 \\
\hline \multicolumn{5}{|l|}{ Cytosolic } \\
\hline Calpain 3 & LGMD2A & $A R$ & $15 q 15.1$ & 253600 \\
\hline TRIM32 & LGMD2H & $A R$ & $9 q 31-34$ & 254110 \\
\hline Myotubularin & Myotubular myopathy & $X L$ & Xq28 & 310400 \\
\hline \multicolumn{5}{|c|}{ Involved in glycosylation } \\
\hline Fukutin & Fukuyama CMD & AR & $9 q 31-33$ & 253800 \\
\hline FKRP & LGMD2I/CMD1C & $A R$ & $19 q 1$ & 606596 \\
\hline POMFnT1 & Muscle-eye-brain CMD & AR & $1 \mathrm{p} 32-34$ & 253280 \\
\hline POMT1 & Walker-Warburg CMD & $A R$ & $9 q 34$ & 236670 \\
\hline \multicolumn{5}{|c|}{ Sarcomeric proteins } \\
\hline Titin & LGMD2J & AR & $2 q$ & \\
\hline Myotilin & LGMD1A & $A D$ & $5 q 22-34$ & 159000 \\
\hline Telethonin & LGMD2G & $A R$ & $17 q 11-12$ & 601954 \\
\hline Actin & Nemaline myopathy & $A D / A R$ & $1 \mathrm{q} 42$ & 101800 \\
\hline & & & & 256030 \\
\hline Tropomyosin 3 & Nemaline myopathy & $A D / A R$ & $1 q 21-23$ & 161800 \\
\hline Tropomyosin 2 & Nemaline myopathy & $A D$ & $9 p 13$ & 190990 \\
\hline Nebulin & Nemaline myopathy & $A R$ & $2 q 21-22$ & 256030 \\
\hline Troponin T1 & Nemaline myopathy & $A R$ & $19 q 13$ & 190990 \\
\hline \multicolumn{5}{|l|}{ Nuclear proteins } \\
\hline Emerin & Emery-Dreifuss MD & $X L$ & Xq28 & 310300 \\
\hline Lamin A/C & LGMD1B & $A D$ & $1 q 11-21$ & 159001 \\
\hline SMN & Spinal muscular atrophy & $A R$ & $5 q 11-13$ & 253300 \\
\hline
\end{tabular}

AD/AR - autosomal dominant and recessive inheritance; BMD - Becker muscular dystrophy; CMD - congenital MD; DMD - Duchenne MD; FKRP - fukutin-related protein; LGMD - limb-girdle MD; SMN - survival motor neuron protein; $\mathrm{XL}$ - X-linked inheritance. MIM number - Mendelian Inheritance in Man; see catalogs of autosomal dominant, autosomal recessive and X-linked phenotypes (Online Mendelian Inheritance in Man, $\mathrm{OMIM}^{\mathrm{T} M}$. McKusick-Nathans Institute for Genetic Medicine, Johns Hopkins University, Baltimore, MD and National Center for Biotechnology Information, National Library of Medicine, Bethesda, MD, 2000. http:// www.ncbi.nlm.nih.gov/omim/). 
progression, to milder forms of later onset and slower progression (for a review, see Ref. 3). Inheritance may be autosomal dominant (LGMD1) or recessive (LGMD2). During the last decade, at least fifteen LGMD genes, six autosomal dominant and ten autosomal recessive, have been mapped. The autosomal dominant forms are relatively rare and probably represent less than $10 \%$ of all LGMD $(3,4)$. The six autosomal dominant LGMD forms are: LGMD1A at 5q22, coding for the protein myotilin (5), LGMD1B at $1 \mathrm{q} 11$, coding for lamin A/C (6), LGMD1C at 3 p25 coding for caveolin-3 (7,8), LGMD1D at $6 \mathrm{q} 23$ (9), LGMD1E at 7q (10), and LGMD1F at 5q31 (11).

Ten autosomal recessive forms have been mapped up to now and most of their protein products have been identified. Four of them, mapped at 17q21, 4q12,13q12 and 5q33, respectively code for $\alpha$-sarcoglycan ( $\alpha$-SG), $\beta$-SG, $\gamma$-SG and $\delta$-SG, that are glycoproteins of the SG subcomplex of the dystrophinglycoprotein complex (DGC) $(12,13)$. Mutations in these genes cause LGMD2C, 2D, $2 \mathrm{E}$ and $2 \mathrm{~F}$, respectively, and constitute a distinct subgroup of LGMD, i.e., the sarcoglycanopathies (for reviews, see Refs. 3 and 4). Among the clinically milder forms,
LGMD2A, at 15q15.1, codes for calpain 3 (14), LGMD2B, at 2p31, codes for dysferlin $(15,16)$, and LGMD2G, at 17q11-12, codes for the sarcomeric telethonin $(17,18)$ (Figure 1). Very recently, the fukitin-related protein (FKRP) gene, mapped at 19q13.3, was identified as the gene responsible for the LGMD2I form (19), as well as the severe form of congenital muscular dystrophy type 1 (CMD1C) (20); the protein TRIM32 has been identified as the gene product of the LGMD2H form (21) at 9q31-33 (22). LGMD2J was recently described in the Finish population as the result of autosomal recessive mutations in the titin gene (23).

Protein studies can provide important information both for the diagnosis and the elucidation of physiological muscle pathways (24).

\section{Xp21 muscular dystrophies}

Dystrophin, the protein product of the $\mathrm{DMD} / \mathrm{BMD}$ gene $(1,2)$, is a large $427-\mathrm{kDa}$ rod-shaped subsarcolemmal protein. Its amino terminus domain binds to actin, and the carboxyl terminus, which is rich in cysteine, links dystrophin to a complex of glycoproteins in the sarcolemma $(12,13,25)$.

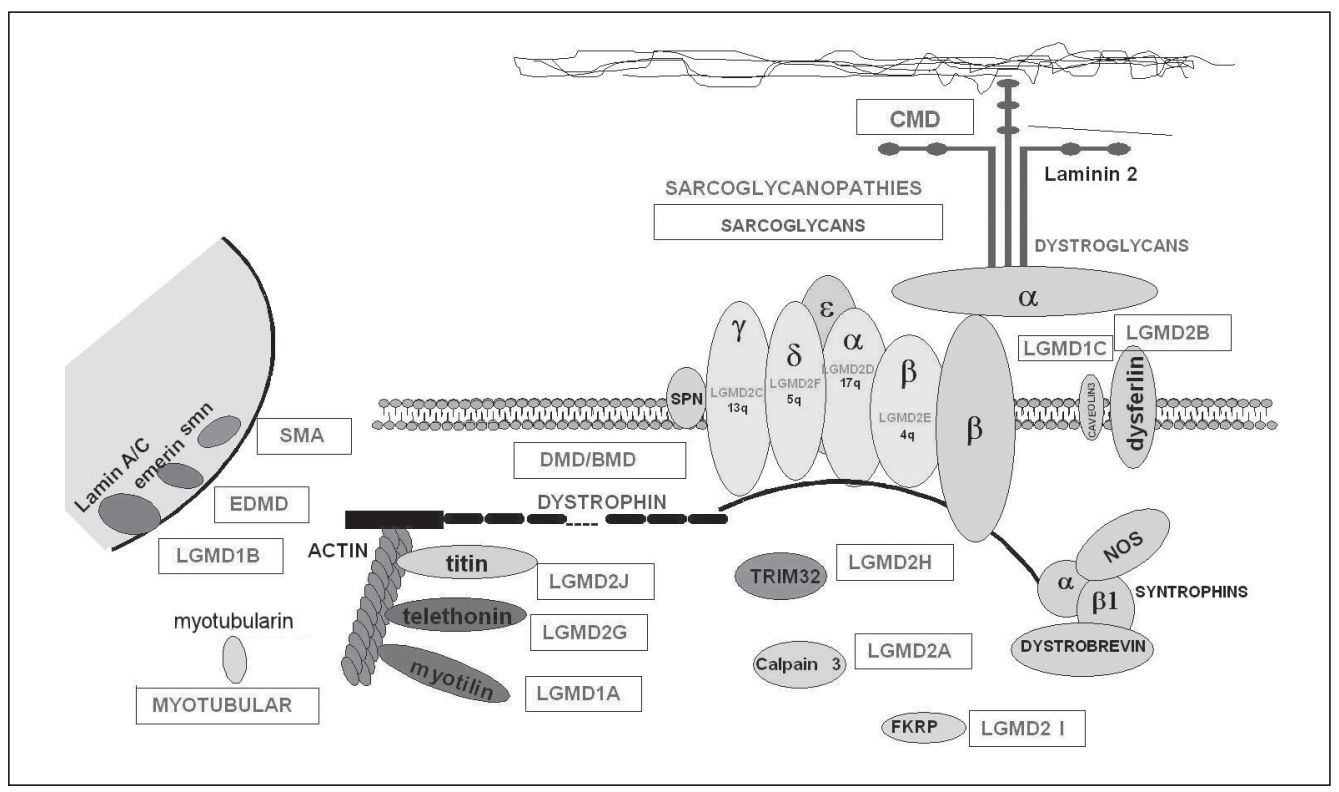

Figure 1. Schematic representation of proteins from the sarcolemma, the sarcomere, the cytosol and the nucleus involved in the process of muscle degeneration in neuromuscular disorders. EDMD - Emery-Dreifuss muscular dystrophy; FKRP fukutin-related protein; NOS - nitric oxide synthase; SMA - spinal muscular atrophy; SPN sarcospan. See Table 1 for other abbreviations. 
The DGC is vital for normal muscle function.

The DGC forms a bridge across the muscle membrane, between the inner cytoskeleton (dystrophin) and the basal lamina (merosin). It has been suggested that DGC stabilizes the sarcolemma and protects muscle fibers from long-term contraction-induced damage and necrosis. The DGC consists of dystroglycan, SG and syntrophin/dystrobrevin subcomplexes (Figure 1). In addition to having a mechanical and structural function, the DGC has been recently suggested to play a role in cellular communication (26). Furthermore, it interacts with the sarcomeric network by binding dystrophin to F-actin (for a review, see Ref. 27).

Clinically, DMD patients show delayed onset of walking, a progressive weakness with difficulty in running, climbing stairs and jumping, frequent falls, and marked calf hypertrophy. The progressive muscle degeneration causes the loss of ambulation at about age 10 and death usually before the end of the second decade due to respiratory or cardiac failure. The milder BMD variant shows a less severe but more variable phenotype, ranging from a slightly less severe DMDlike condition to a very mild condition. Some patients may be able to walk throughout their lives. A patient is classified as DMD when wheelchair-dependent before the age of 13 years, and as BMD, when able to walk beyond age 16 (for a review, see Ref. 28).

About two thirds of DMD patients have a frame-shifting deletion in the dystrophin gene, while the remaining ones have point mutations or small deletions or rearrangements. All of these mutations lead to deficiency of the protein dystrophin in muscle (2).

Antibodies against epitopes in the $\mathrm{N}$ terminal and C-terminal domains of dystrophin have been used in the analysis of more than 400 DMD patients from our laboratory. Almost all DMD patients are found to be dystrophin deficient when the C-terminal antibody is used. However, a variable proportion (4-30\%) of dystrophin-positive isolated or grouped fibers (called revertant fibers) are observed in most of them, mainly with the N-terminal antibody (Figure 2). This small amount of dystrophin can be observed as faint bands by Western blotting, but is not
A
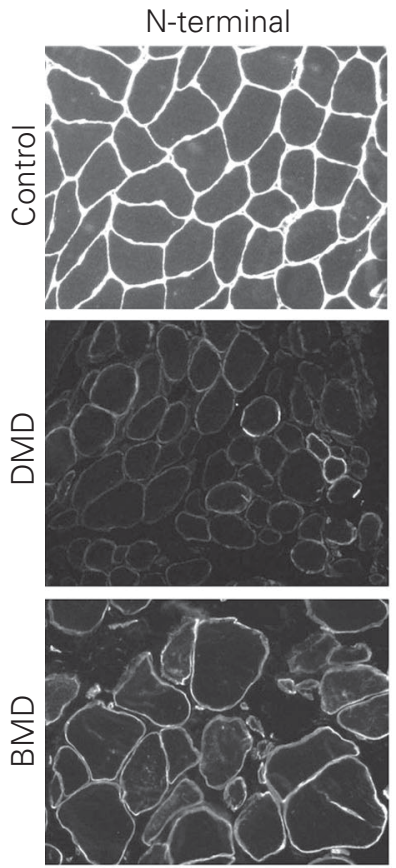

C-terminal
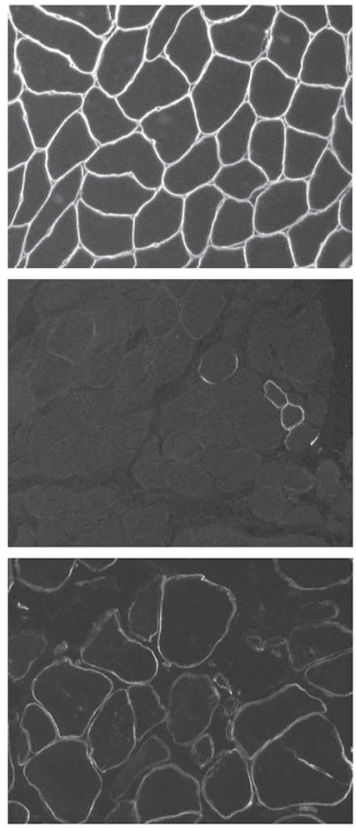

B

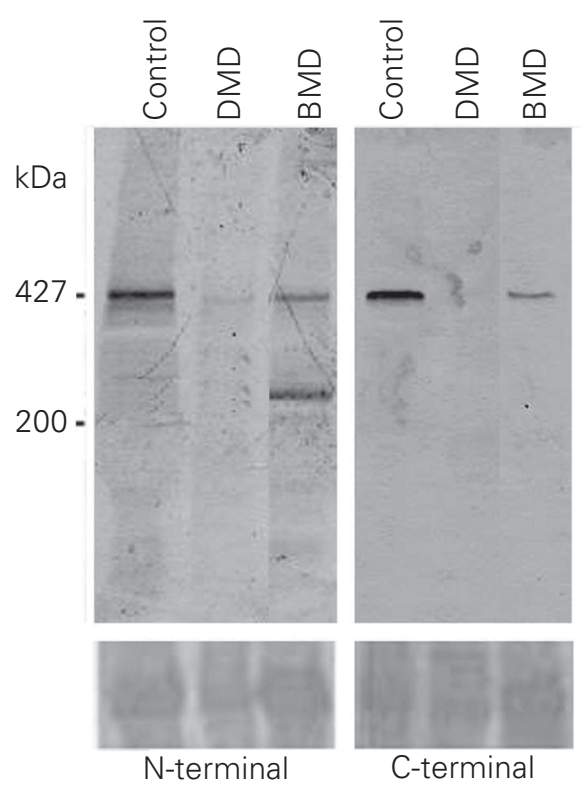


correlated with the clinical course (29-31). This observation should be taken into account before assessing the effect of any therapeutic trial with the replacement of dystrophin through gene or cell therapy.

A correlation between the amount of dystrophin and the severity of the phenotype has been suggested $(2,29)$. However, in our experience, patients with an intermediate clinical phenotype between DMD and BMD (outlier patients) usually show the same dystrophin-deficient pattern as classical DMD $(30,31)$.

In about 100 BMD patients, a positive immunofluorescence pattern was observed in $~ 90 \%$ of cases, with a variable degree of patchiness (Figure 2). Western blot detected bands of altered molecular weight or in reduced amount. Surprisingly, some mildly affected patients showed significant dystrophin deficiency, while some severely affected patients showed large amounts of the protein in muscle (32). In addition, BMD patients with mutations of exons 45 to 49 often present two dystrophin bands when Nterminal antibodies are used (Figure 2) (33).

\section{Sarcoglycanopathies}

The sarcoglycanopathies are usually the most severe forms of LGMD (34). The four known components of the SG complex include $\alpha$-SG, $\beta$-SG, $\gamma$-SG, and $\delta$-SG. They are assembled in a complex which is inserted into the membrane. Mutations in one of the four SG proteins cause LGMD2C, 2D, $2 \mathrm{~F}$ and 2E, respectively. Many different mutations have already been identified in all the SG genes, including missense, splicing and nonsense mutations, and small and large gene deletions [listed at http://www.dmd.nl]. Our group recently reported the spectrum of mutations in 35 Brazilian sarcoglycanopathy families (35). The main findings suggested that screening of sarcoglycanopathies in Brazil should start by detecting mutations $\alpha-\mathrm{SG} /$ c. 229C $>\mathrm{T}$ and $\gamma-\mathrm{SG} / \mathrm{c} .521 \mathrm{del}$, followed by $\delta$-SG/c.656delC, since they were found to correspond to 26,23 and $11 \%$ of the disease alleles. Therefore, screening for these three mutations would permit the diagnosis of $\sim 60 \%$ of Brazilian sarcoglycanopathy patients (35).

In most muscle biopsies from patients with a primary sarcoglycanopathy, the primary loss or deficiency of any one of the four SG, $\beta-S G$ and $\delta$-SG in particular, leads to a secondary deficiency of the whole subcomplex (Figure 3) $(3,4,26,36,37)$. However, exceptions may occur, such as the deficiency of $\gamma$-SG with a partial preservation of the other three SG in LGMD2C (37) or the partial deficiency of only $\alpha$-SG with the retention of the other three in LGMD2D $(36,38)$. The observation of a complete deficiency of one SG with partial deficiency of the others may help to indicate which gene should be first screened for mutations.

Patients with primary SG mutations and deficiency of the protein may have a secondary reduction in dystrophin, particularly patients with primary $\gamma$-SG deficiency. This
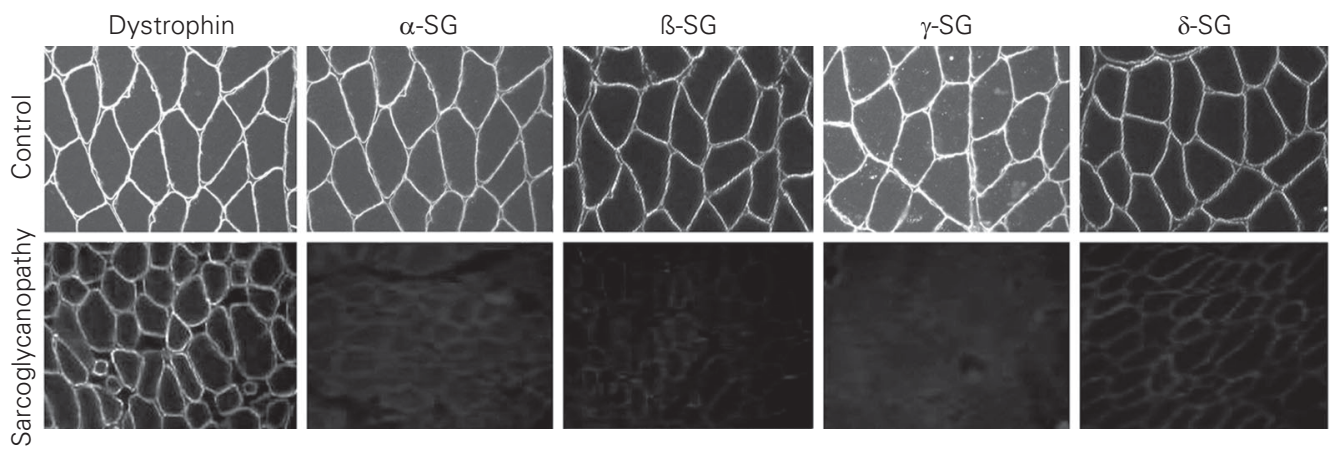

Figure 3. Immunofluorescence analysis for dystrophin and the four sarcoglycan (SG) proteins in a control, and in one sarcoglycandeficient patient (LGMD2C). 
Figure 4. Multiplex Western blot analysis for dystrophin (rod domain antibody), dysferlin and calpain 3 in a normal control and in patients with limb-girdle 2A (LGMD2A), 2B, Becker (BMD) and Duchenne muscular dystrophies (DMD). The arrows indicate the altered protein bands. suggests that $\gamma$-SG might interact more directly with dystrophin (37). Therefore, a relative dystrophin deficiency may occur in nonBMD, and this should be taken into consideration for differential diagnosis.

\section{Calpainopathy}

Calpain 3, a muscle-specific 94-kDa calcium-activated neutral protease 3 , binds to titin. It is a cysteine protease which plays a role in the disassembly of sarcomeric proteins, but it may also have a regulatory role in the modulation of transcription factors. The loss of its function leads to activation of other proteases.

Mutations in the calpain 3 gene at 15q15 cause LGMD2A (14). LGMD2A patients present a wide range of distinct pathogenic mutations distributed along the entire length of the calpain 3 gene. Interestingly, Brazilian LGMD2A patients showed some prevalent mutations concentrated in six exons (39).

The study of calpain 3 protein in muscle

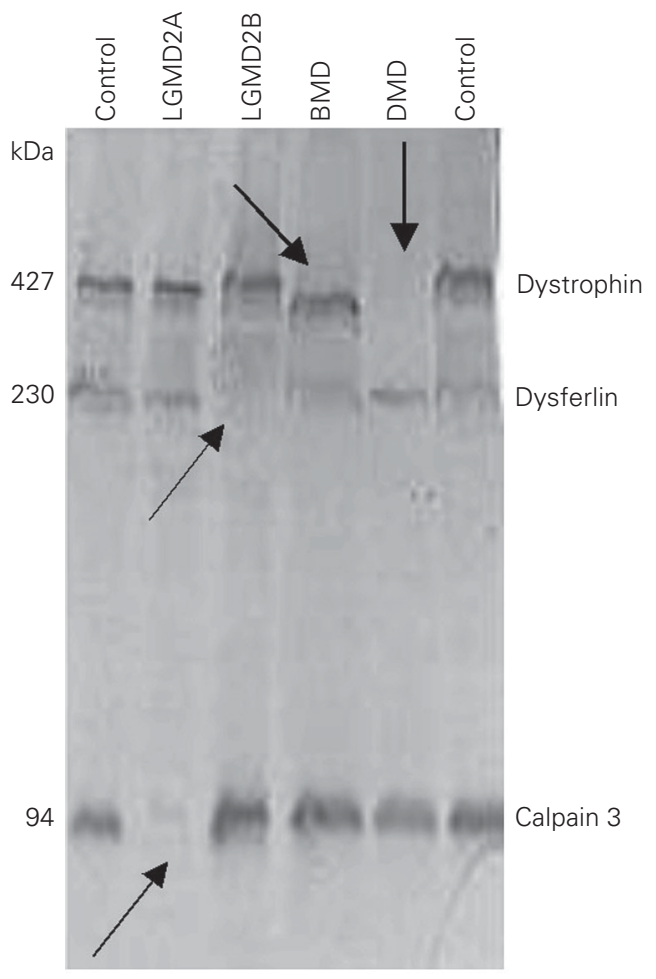

at this time can only be carried out by Western blotting since the antibodies available do not react on sections. A first trial can be done by multiplex Western blot analysis for dystrophin, dysferlin and calpain (Figure 4). If a reduction is suspected, a new blot specific for calpain antibodies is performed on $13 \%$ gel, and the presence of the three possible calpain 3 bands is analyzed. In vitro degradation of the muscle extract may lead to misleading results which should be interpreted with care. LGMD2A patients can show total, partial, or more rarely, no calpain 3 deficiency at all, and no direct correlation has been observed between the amount of calpain and the severity of the phenotype. Very low levels or no expression of calpain 3 were observed in European and Brazilian patients with a clinical course varying from mild to severe $(40,41)$. LGMD2A patients with missense mutations may present a faint or almost normal $94-\mathrm{kDa}$ calpain band $(39,40)$, suggesting that some mutations may affect protein function without eliminating the protein from muscle.

A normal amount of calpain was found in sarcoglycanopathies $(40,41)$, and normal SG proteins were observed in calpain 3-deficient LGMD2A patients (37), suggesting no direct relationship between calpain 3 and the SG complex. In addition, normal calpain bands in LGMD2G patients also suggest no correlation with telethonin (42).

However, an unexpected reduction of calpain 3 was observed in LGMD2B patients, suggesting a possible association between calpain 3 and dysferlin, which requires further study $(41,43,44)$. Subsequently, several studies have shown that a secondary reduction of calpain 3 may occur in other myopathies such as LGMD2I (45) and LGMD2J (23).

\section{Dysferlinopathies}

Dysferlin, coded by a gene on $2 \mathrm{p} 12-14$, is a ubiquitously expressed 230-kDa molecule 
localized in the periphery of muscle fibers, linked to the sarcolemmal membrane (46). Dysferlin can be detected also in blood, skin and in chorionic villus biopsies $(44,47)$.

Two distinct phenotypes are associated with mutations in this gene: Miyoshi myopathy, with a predominantly distal muscle wasting (16), and LGMD2B, with a proximal weakness (15). So far, due to the large size of the dysferlin gene (55 exons), only a few mutations have been identified, and no apparent hot spot for mutations has been found. Therefore, muscle protein analysis is essential for diagnostic purposes.

Protein analyses in LGMD2B have shown a total deficiency of dysferlin both by immunofluorescence and Western blotting (Figures 4 and 5). Although a partial deficiency has been reported in LGMD2B patients (46), dysferlin deficiency seems to be specific to LGMD2B in our patients, and has not been seen as a secondary effect in other forms of muscular dystrophy (44).

A normal localization and a normal molecular weight for dysferlin have been found in DMD and sarcoglycanopathies, suggesting no interaction between dysferlin and the DGC. A possible association between dysferlin and caveolin-3 has recently been described (48). It is important to point out that mutations in the caveolin-3 gene cause a rare form of autosomal dominant muscular dystrophy, as well as rippling muscle disease (7). Mutation in the caveolin-3 gene leads to a typical loss of caveolin immunolabeling, suggesting a dominant negative effect (7).

\section{Sarcomeric proteins in myopathies}

The sarcomere is the unit of skeletal and cardiac muscle contraction. In the past few years, many studies have focused on the role of skeletal and cardiac muscle proteins (49). Mutations in the genes for several sarcomeric proteins such as telethonin (18) and myotilin (5) have been detected in different forms of muscular dystrophies. In addition, mutations in five different sarcomeric genes, actin, tropomyosin 3 and 2, nebulin and troponin $\mathrm{T} 1$, have been identified as the cause of Nemaline myopathy, a congenital myopathy characterized by the presence of rod-like bodies inside muscle fibers (for a review, see Ref. 50). Clinically, Nemaline myopathy is associated with muscle weakness, respiratory and feeding difficulties at birth, an elongated face and skeletal deformities. The autosomal recessive form appears to be the most common one and is caused by mutations in the nebulin gene. Nebulin is a large protein of $800 \mathrm{kDa}$, and its $\mathrm{C}$-terminus integrates into the Z-disk while the N-terminus projects into the I-band. Nebulin may provide a molecular template
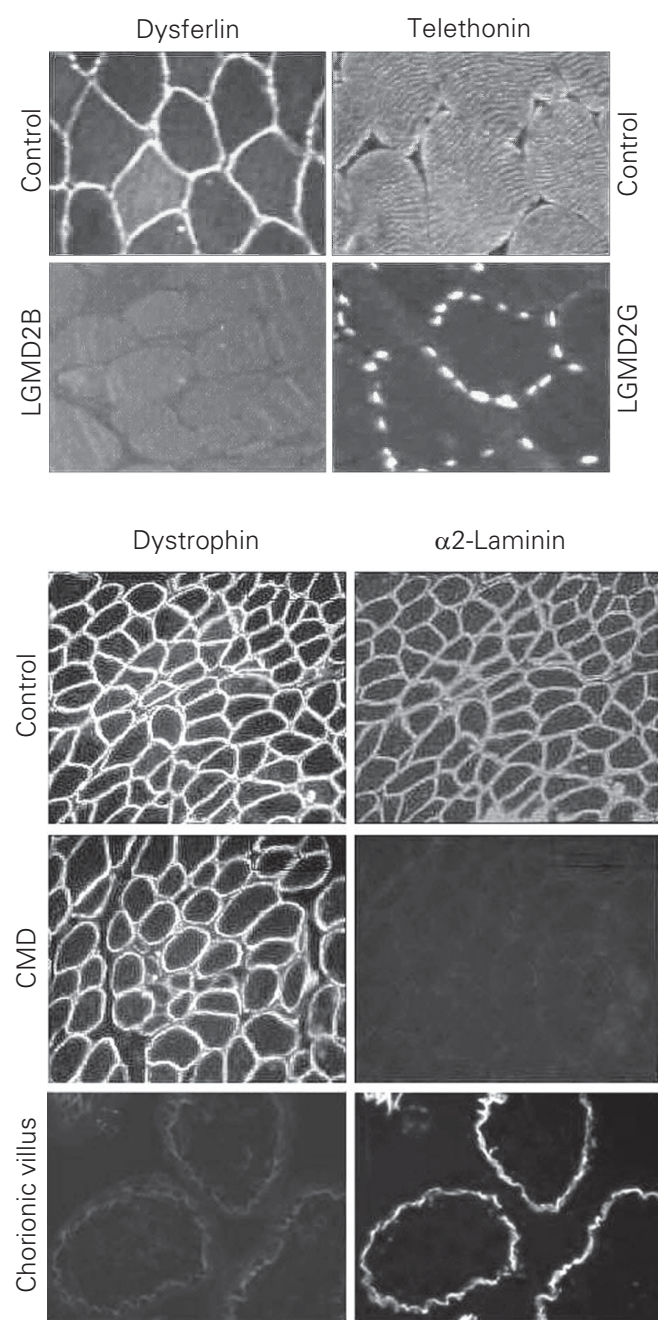

Figure 5. Dysferlin and telethonin study by immunofluorescence analysis showing the normal sarcolemmal dysferlin pattern in the control muscle, and the negative pattern in one LGMD2B patient. Note the sarcomeric telethonin labeling in one control and the negative sarcomeric pattern in one LGMD2G patient. LGMD, limbgirdle muscular dystrophy.

Figure 6. Double-immunofluorescence analysis for dystrophin and $\alpha 2$-laminin showing the normal sarcolemmal pattern in a normal control, the absence of $\alpha 2$-laminin in one congenital muscular dystrophy (CMD) patient, and a positive pattern in a normal sample of a chorionic villus. 
to regulate the length of the actin filament. We have recently identified a patient with Nemaline myopathy, with a deficiency of only the SH3 domain of nebulin by Western blot analysis (51).

Myotilin is a novel $57-\mathrm{kDa}$ cytoskeletal protein coded by a gene mapped at $5 \mathrm{q} 3$. It is expressed in skeletal and cardiac muscle, and it co-localizes with $\alpha$-actinin in the sarcomeric I-band. Its N-terminal sequence is unique, but the $\mathrm{C}$-terminal half contains two Ig-like domains homologous to domains in titin. Titin acts as a molecular ruler for the assembly of the sarcomere by providing spatially defined binding sites for other sarcomeric proteins. Mutations in the myotilin gene cause the autosomal dominant form of LGMD1A, but muscle myotilin protein is apparently normal (5).

Telethonin is a sarcomeric protein of 19 $\mathrm{kDa}$ present in the Z-disk of the sarcomere of striated and cardiac muscle (17). Mutations in the telethonin gene at $17 \mathrm{q}$ cause LGMD2G (18). Telethonin was found to be one of the substrates of the serine kinase domain of titin. The specific function of telethonin and its interaction with other muscle proteins are still unknown.

DNA analysis in six Brazilian patients from four unrelated families showed that all had the same frameshift mutation in the telethonin gene and deficiency of the telethonin protein in muscle (Figure 5). Since telethoninopathy has not been reported in other patients except the Brazilian ones, the existence and effect of other mutations are still unknown.

Additional protein studies on these patients have shown normal expression of dystrophin, SG, dysferlin, calpain 3 and titin. Immunofluorescence analysis for $\alpha$-actinin2 and myotilin showed a normal cross-striation pattern, suggesting that at least part of the Z-line of the sarcomere is preserved. Ultrastructural analysis confirmed the maintenance of the integrity of the sarcomeric architecture. Therefore, mutations in the tele- thonin gene do not seem to alter the sarcomere integrity (42).

The analysis of telethonin in muscle biopsies from patients with LGMD2A, LGMD2B, sarcoglycanopathies and DMD showed normal localization, suggesting that the deficiency of calpain, dysferlin, SG and dystrophin does not seem to alter telethonin expression (42). Telethonin was clearly present in the rods in muscle fibers from patients with Nemaline myopathy, confirming its localization in the Z-line of the sarcomere.

More recently, homozygous mutations in the titin gene previously known to be responsible for autosomal dominant tibial muscular dystrophy, a form prevalent in Finland, were found to cause a proximal LGMD, LGMD2J. A secondary reduction in calpain 3 was observed in these patients (23).

The identification of new protein components of the sarcomere, such as ZASP, FATZ and Ankrd2, using the two-hybrid or other protein interaction techniques, is continuously increasing. The role of most of these proteins is still unknown. However, so far no disease has been associated with any of them, suggesting that total deficiency is probably incompatible with life, and therefore that they play an essential role in the constitution of the sarcomere.

\section{Fukutin-related protein}

Fukutin is the protein product of the Fukuyama form of CMD, a multisystem disease affecting the brain as well as skeletal and cardiac muscles. The function of fukutin is still unknown. An FKRP was recently identified, with sequence similarities to a family of proteins involved in the glycosylation of cell surface molecules (19). Mutations in the FKRP gene were identified in both LGMD2I and CMD type 1C (CMD-1C) $(19,20)$, both previously mapped to an identical region on chromosome 19q13.3. CMD is characterized by onset of symptoms within the first few months of life, and in the $1 \mathrm{C}$ 
form there is inability to walk. The LGMD2I form is characterized by a high variability in clinical course, with a spectrum of phenotypes ranging from a Duchenne-like disease course including cardiomyopathy to milder phenotypes with a slow progression (20). Secondary protein abnormalities are common in this group of diseases, including a reduction of $\alpha 2$-laminin labeling, mainly on immunoblots, reduced Western blot labeling for B1-laminin, and secondary reduction of calpain 3. A variable reduction of $\alpha$-dystroglycan expression was also observed in skeletal muscle biopsies from affected individuals, with a reduction in molecular weight observed by immunoblotting, which could indicate a glycosylation defect associated with this disease. Therefore, until a proper antibody against FKRP is developed, muscle protein analysis showing a relative secondary deficiency of $\alpha$-dystroglycan and $\alpha 2-$ laminin might suggest the diagnosis of LGMD2I. This diagnosis should be confirmed by molecular analysis.

\section{Myotubularin}

Myotubularin is the protein product of the X-linked MTM1 gene. Mutations in this gene cause the most severe neonatal (and lethal) form of myotubular myopathy (XLMTM) (for a review, see Ref. 52). XLMTM is a congenital myopathy characterized by small muscle fibers with central nuclei resembling fetal myotubes. Through computer-based analysis of the predicted protein structure, myotubularin has been classified as a member of the protein tyrosine phosphatase family. It has been suggested that myotubularin is required for muscle cell differentiation, and that it exerts an important regulatory function during myogenesis.

\section{Nuclear proteins in neuromuscular disorders}

Emerin is a membrane-spanning $34-\mathrm{kDa}$ serine-rich protein which is a component of the nuclear lamina associated with the nuclear envelope. The emerin gene has been mapped to Xq28, and mutations were found in the Xlinked inherited Emery-Dreifuss dystrophy (53). One postulated function of emerin is to stabilize the nuclear membrane and provide structural support in an environment in which the nucleus is subject to mechanical stress.

Lamin A/C belongs to a family of nuclear laminar proteins which co-localizes with emerin. It is coded by a gene on chromosome 1 (1q11-23). Abnormalities in the gene for lamin A are associated with an autosomal dominant illness that is clinically identical to emerin deficiency, the LGMD1B form (54).

The survival motor neuron (SMN) gene product is the altered protein responsible for spinal muscular atrophy, an autosomal recessive neuromuscular disorder characterized by degeneration of motor neurons of the spinal cord. In humans, the SMN gene is found as two almost identical copies on chromosome 5, denoted SMN1 (telomeric) and SMN2 (centromeric), differing by just five nucleotides that undergo alternative splicing of exons 5 and 7 (55). SMN is both a cytoplasmic protein and a nuclear protein located in structures called "gems" (56). Studies characterizing the SMN protein are emerging.

\section{Extracelullar matrix proteins}

$\alpha 2$-Laminin is a constituent of the basal lamina which links to dystroglycan and which provides structural support in the extracellular matrix. It is composed of three chains: $\alpha 2, \beta 1$ and $\gamma 1$. $\alpha 2$-Laminin deficiency due to mutations in the LAMA2 gene at $6 \mathrm{q} 2$ is the cause of the autosomal recessive CMD (57). $\alpha 2$-Laminin is totally deficient in muscle biopsies from patients with the severe CMD phenotype (Figure 6). Partial deficiencies have been described in patients with heterogeneity in the clinical picture (52). The protein is detected in skin biopsies as well as in 
chorionic villi, and therefore is a very useful marker for prenatal diagnosis.

We have studied 20 patients affected by CMD and detected a total deficiency of $\alpha 2-$ laminin in all of them using both the 80 - and 300-kDa antibodies (58). In patients with partial deficiency, usually the $300-\mathrm{kDa}$ antibody shows a more deficient pattern (59). A partial deficiency of only the $300-\mathrm{kDa} \alpha 2-$ laminin antibody was recently detected in patients with the classical LGMD clinical course (60). In addition, secondary deficiency of $\alpha 2$-laminin has been found in CMD1C and LGMD2I $(19,20)$. Screening for mutations in the LAMA2 gene can help elucidate the primary or secondary etiology of these deficiencies.

In addition to $\alpha 2$-laminin deficiency, marked alterations in the glycosylation of $\alpha$ dystroglycan have been very recently associated with some forms of severe CMD (Fukuyama, Walker-Warburg, muscle-eyebrain and FKRP forms). Mutations in genes with glucosyltransferase activity have been identified as responsible for these diseases, suggesting that abnormal processing of $\alpha$ dystroglycan may be central to the pathogenesis of a significant number of genetic conditions (61).

Recessive mutations in the COL6A2 gene cause Ullrich CMD, a severe muscle weakness disease associated with multiple joint contractures and deficiency of collagen VI in tissues. On the other hand, dominant mutations in the same gene may cause Bethlem myopathy, a skeletal muscle myopathy with a large spectrum of clinical variability also associated with contractures. Therefore, autosomal recessive or dominant mutations in the same gene may cause clinically different diseases (62).

\section{Protein study for differential diagnosis}

Testing for defective protein expression is a powerful tool for deciding where to start the search for gene mutations, particularly in the more prevalent forms of neuromuscular disorders.

Male patients with suspected X-linked dystrophy are first tested for deletions in the dystrophin gene by DNA analysis in blood samples, because this is a less invasive test. The identification of a gene deletion will confirm the diagnosis of DMD/BMD in about $60 \%$ of cases. If no deletion is detected, a muscle biopsy is required for the analysis of muscle proteins in an attempt to elucidate the possible diagnosis. Dystrophin is the first protein to be tested, using N- and Cterminal epitope antibodies. A significant deficiency of dystrophin is suggestive of DMD or severe BMD. Complementary Western blot analysis will confirm the amount of protein present, and a possible prognosis based on dystrophin quantity and the presence or absence of the different domains.

If an autosomal form is suspected, complementary studies for $\alpha-S G$ and $\gamma$-SG in a double reaction with an $\mathrm{N}$-terminal antibody for dystrophin are conducted. If a deficiency of any of the SG is detected, additional studies for $\beta-S G$ and $\delta$-SG are conducted to confirm a possible sarcoglycanopathy. For the final diagnosis of a sarcoglycanopathy, mutation screening should start with $\alpha$-SG since this is the cause of the most prevalent sarcoglycanopathy. If $\gamma-\mathrm{SG}$ is predominantly absent, a $\gamma$-sarcoglycanopathy should be suspected first.

Another possibility for male patients who are dystrophin-positive, but with early contractures and cardiomyopathy could be Emery-Dreifuss muscular dystrophy. In such cases, immunofluorescence analysis for emerin should be done, and a negative nuclear labeling would confirm the diagnosis.

Additional immunofluorescence analyses for $\alpha 2$-laminin using the $300-\mathrm{kDa}$ antibody should be done in more severely affected patients. The diagnosis of total or partial $\alpha 2$-laminin deficiency is confirmed using an additional antibody ( $80 \mathrm{kDa})$ against 
the N-terminal region. Partial $\alpha 2$-laminin deficiencies might be associated with a diagnosis of MDC1C or LGMD2I, but the deficiency needs to be confirmed by mutational analysis. Western blot analysis for $\alpha$-dystroglycan glycosylation can also add some information about new genes related to alterations in this process, such as LGMD2I, and to other forms of CMD.

In adult onset muscular dystrophy forms, multiplex Western blot analysis for dystrophin, calpain and dysferlin, as well as telethonin analysis by immunofluorescence, has proved to be very useful for preliminary diagnosis of muscular dystrophy. A dystrophin deficiency is first suggestive of Xp21 muscular dystrophy. However, small reductions can also be observed in sarcoglycanopathies and LGMD2I. Calpain 3 may occur as a secondary effect of other forms of muscular dystrophy, but dysferlin and telethonin deficiency have been shown so far to be the consequence of their respective primary gene defect. Therefore, the absence of dysferlin or telethonin in a muscle biopsy strongly suggests a diagnosis of LGMD2B or LGMD2G, respectively.

When a deficiency of calpain 3 is detected and no mutations in the calpain 3 gene are found, the possibility of dysferlin-, FKRPand titin-associated conditions should be considered, mainly if the deficiency is partial.

If no protein or DNA alterations are found in patients with a clinical diagnosis of LGMD, the possibility of spinal muscular atrophy should be considered due to the clinical overlap between these diseases.

For the remaining proteins described here (mainly the sarcomeric ones), for which no clear deficiency has been previously described associated with their respective primary defect, protein testing is not useful for diagnostic purposes. In this respect, the development of new methodologies for the identification of subtle protein alterations are of the utmost importance, not only for the diagnosis, but also for understanding interactions among proteins in order to elucidate genotype/phenotype interaction in neuromuscular diseases.

\section{Acknowledgments}

The collaboration of the following persons is gratefully acknowledged: Marta Cánovas for invaluable technical help, and Dr. Maria Rita Passos-Bueno, Dr. Eloisa S. Moreira, Dr. Rita C.M. Pavanello, Dr. Ivo Pavanello, Dr. Acary S.B. Oliveira, Dr. Edmar Zanotelli, Cleber da Silva Costa, Viviane P. Muniz, Telma Gouveia, Bruno Lima, Helena Lima, Lydia U. Yamamoto, Flavia de Paula, Alessandra Starling, Antonia Cerqueira, Constancia Urbani, Janet Tajchman, and Ms. Lucete Cesana. We would also like to thank the following researchers, who kindly provided specific antibodies: L.V.B. Anderson, A. Beggs, J. Chamberlain, L.M. Kunkel, C. Bonnemann, E.E. McNally, V. Nigro, Z. Labeit, O. Carpen, G. Faulkner, G. Valle, E. Hoffmann, R. Worton, E. Ozawa, K. Campbell, N. Thi Man, and G. Morris. Very special thanks are due to Dr. ZubrzyckaGaarn (in memoriam), Dr. Peter Ray and Dr. Ron Worton, who opened their laboratory to introduce us to Western blot studies.

\section{References}

1. Koenig M, Monaco AP \& Kunkel LM (1988). The complete sequence of dystrophin predicts rod-shaped cytoskeletal protein. Cell, 53: 219228.

2. Hoffman EP, Brown RH \& Kunkel LM (1987). Dystrophin: the protein product of the Duchenne muscular dystrophy locus. Cell, 51: 919928.
3. Bushby KMD (1999). The limb-girdle muscular dystrophies - multiple genes, multiple mechanisms. Human Molecular Genetics, 8: 18751882.

4. Zatz M, Vainzof M \& Passos-Bueno MR (2000). Limb-girdle muscular dystrophy: one gene with different phenotypes, one phenotype with different genes. Current Opinion in Neurology, 13: 511-517. 
5. Hauser MA, Horrigan SK, Salmikangas $P$, Viles KD, Tim RW, Torian UM \& Anu T (2000). A mutation in the Myotilin gene causes limbgirdle muscular dystrophy 1A. Human Molecular Genetics, 9: 2141 2147.

6. Van der Kooi A, Van Meegen M, Ledderhof TM, McNally EM, de Visser M \& Bolhuis PA (1997). Genetic localization of a newly recognized autosomal dominant limb-girdle muscular dystrophy with cardiac involvement (LGMD1B) to chromosome 1q11-21. American Journal of Human Genetics, 60: 891-895.

7. Minetti C, Sotgia F, Bruno C et al. (1998). Mutations in the caveolin3 gene cause autosomal dominant limb-girdle muscular dystrophy. Nature Genetics, 18: 365-368.

8. McNally EM, de Sa Moreira E, Duggan DJ et al. (1998). Caveolin-3 in muscular dystrophy. Human Molecular Genetics, 7: 871-878.

9. Messina DI, Speer MC, Pericak-Vance MA \& McNally EM (1997). Linkage of familial dilated cardiomyopathy with conduction defect and muscular dystrophy to chromosome 6q23. American Journal of Human Genetics, 61: 909-917.

10. Speer MC, Vance JM, Grubber JM et al. (1999). Identification of a new autosomal dominant limb-girdle muscular dystrophy locus on chromosome 7. American Journal of Human Genetics, 64: 556-562.

11. Feit H, Silbergleit A, Schneider LB et al. (1998). Vocal cord and pharyngeal weakness with autosomal dominant distal myopathy: clinical description and gene localization to 5q31. American Journal of Human Genetics, 63: 1732-1742.

12. Ervasti JM, Ohlendieck K, Kahl SD, Gaver MG \& Campbell KP (1990). Deficiency of a glycoprotein component of the dystrophin complex in dystrophic muscle. Nature, 345: 315-319.

13. Yoshida M \& Ozawa E (1990). Glycoprotein complex anchoring dystrophin to sarcolemma. Journal of Biochemistry, 108: 748-752.

14. Richard I, Broux O, Allamand V et al. (1995). Mutations in the proteolytic enzyme calpain 3 cause limb-girdle muscular dystrophy type 2A. Cell, 81: 27-40.

15. Bashir R, Britton S, Strachan T et al. (1998). A gene related to the $C$. elegans spermatogenesis factor fer- 1 is mutated in patients with limb-girdle muscular dystrophy type 2B (LGMD2B). Nature Genetics, 20: 37-42.

16. Liu J, Aoki M, Illa I et al. (1998). Dysferlin, a novel skeletal muscle gene, is mutated in Miyoshi myopathy and limb girdle muscular dystrophy. Nature Genetics, 20: 31-36.

17. Valle G, Faulkner G, De Antoni A, Pacchioni B, Pallavicini A, Pandolfo D, Tiso N, Toppo S, Trevisan S \& Lanfranchi G (1997). Telethonin, a novel sarcomeric protein of heart and skeletal muscle. FEBS Letters, 415: 163-168.

18. Moreira ES, Wiltshire TJ, Faulkner G et al. (2000). Limb-girdle muscular dystrophy type $2 \mathrm{G}$ (LGMD2G) is caused by mutations in the gene encoding the sarcomeric protein telethonin. Nature Genetics, 24: 163-166.

19. Brockington M, Blake DJ, Prandini P et al. (2001). Mutations in the fukutin-related protein gene (FKRP) cause a form of congenital muscular dystrophy with secondary laminin alpha2 deficiency and abnormal glycosylation of alpha-dystroglycan. American Journal of Human Genetics, 69: 1198-1209

20. Brockington M, Yuva Y, Prandini P et al. (2001). Mutations in the fukutin-related protein gene (FKRP) identify limb girdle muscular dystrophy $2 \mathrm{l}$ as a milder allelic variant of congenital muscular dystrophy MDC1C. Human Molecular Genetics, 10: 2851-2859.

21. Frosk $P$, Weiler $T$, Nylen E, Sudha T, Greenberg CR, Morgan K, Fujiwara TM \& Wrogemann K (2002). Limb-girdle muscular dystrophy type $2 \mathrm{H}$ associated with mutation in TRIM32, a putative E3ubiquitin-ligase gene. American Journal of Human Genetics, 70:
663-672.

22. Weiler T, Greenberg CR, Zelinski T, Nylen E, Coghlan G, Crumley MJ, Fujiwara TM, Morgan K \& Wrogemann K (1998). A gene for autosomal recessive limb-girdle muscular dystrophy in Manitoba Hutterites maps to chromosome region 9q31-q33: evidence for another LGMD locus. American Journal of Human Genetics, 63: 140-147.

23. Haravuori H, Vihola A, Straub V et al. (2001). Secondary calpain3 deficiency in 2q-linked muscular dystrophy: titin is the candidate gene. Neurology, 56: 869-877.

24. Anderson LVB (2001). Multiplex Western blot analysis of the muscular dystrophy proteins. In: Bushby KMD \& Anderson LVB (Editors), Muscular Dystrophy: Methods and Protocols. Chapter 22 (number 43 in the Methods in Molecular Medicine series). Humana Press, Totowa, NJ, 369-386.

25. Campbell KP \& Kahl SD (1989). Association of dystrophin and an integral membrane glycoprotein. Nature, 338: 259-262.

26. Hack AA, Groh ME \& McNally EM (2000). Sarcoglycans in muscular dystrophy. Microscopy Research and Technique, 48: 167-180.

27. Cohn RD \& Campbell KP (2000). Molecular basis of muscular dystrophies. Muscle and Nerve, 23: 1456-1471.

28. Bakker E \& Van Ommen GB (1998). Duchenne and Becker muscular dystrophy (DMD and BMD). In: Emery AEH (Editor), Neuromuscular Disorders: Clinical and Molecular Genetics. John Wiley \& Sons, New York, 59-85.

29. Nicholson LV, Johnson MA, Gardner-Medwin G, Bhattacharya S \& Harris JB (1990). Heterogeneity of dystrophin expression in patients with Duchenne and Becker muscular dystrophy. Acta Neuropathologica, 80: 239-250

30. Vainzof M, Pavanello RCM, Pavanello I, Passos-Bueno MR, Rapaport D \& Zatz M (1990). Dystrophin immunostaining in muscles from patients with different types of muscular dystrophy: A Brazilian study. Journal of Neurological Sciences, 98: 221-233.

31. Vainzof M, Zubrzycka-Gaarn EE, Rapaport D, Passos-Bueno MR, Pavanello I \& Zatz MZ (1991). Immunofluorescence dystrophin study in Duchenne dystrophy through the concomitant use of two antibodies directed against the carboxy-terminal and the amino-terminal region of the protein. Journal of Neurological Sciences, 101: 141147.

32. Vainzof M, Passos-Bueno MR, Pavanello RCM \& Zatz M (1995). Is dystrophin always altered in Becker muscular dystrophy patients? Journal of Neurological Sciences, 131: 99-104.

33. Vainzof M, Passos-Bueno MR, Rapaport D, Pavanello RCM, Bulman DE \& Zatz M (1992). Additional dystrophin fragment in Becker muscular dystrophy patients: Correlation with the pattern of DNA deletions. American Journal of Human Genetics, 44: 382-384.

34. Vainzof M, Passos-Bueno MR, Pavanello RCM, Marie SK \& Zatz M (1999). Sarcoglycanopathy is responsible for $68 \%$ of severe autosomal recessive limb-girdle muscular dystrophy. Journal of Neurological Sciences, 164: 44-49.

35. Moreira ES, Vainzof M, Suzuki OT, Pavanello RCM, Zatz M \& PassosBueno MR (2003). Genotype-phenotype correlations in 35 Brazilian families with sarcoglycanopathies including the description of three novel mutations. Journal of Medical Genetics, 40: E12.

36. Bönnemann CG (1999). Limb-girdle muscular dystrophies: an overview. Journal of Child Neurology, 14: 31-33.

37. Vainzof M, Passos-Bueno MR, Moreira ES et al. (1996). The sarcoglycan complex in the six autosomal recessive limb-girdle (ARLGMD) muscular dystrophies. Human Molecular Genetics, 5: 19631969.

38. Vainzof M, Moreira ES, Canovas M, Suzuki OT, Pavanello RCM, 
Costa CS, Passos-Bueno MR \& Zatz M (2000). Partial $\alpha$-sarcoglycan deficiency associated with the retention of the SG complex in a LGMD2D family. Muscle and Nerve, 23: 984-988.

39. Paula F, Vainzof M, Passos-Bueno MR, Pavanello RCM, Matioli SR, Anderson LVB, Nigro V \& Zatz M (2002). Clinical variability in calpainopathy: What makes the difference? European Journal of Human Genetics, 10: 825-832.

40. Anderson LV, Davison K, Moss JA, Richard I, Fardeau M, Tome FM, Hubner C, Lasa A, Colomer J \& Beckmann JS (1998). Characterization of monoclonal antibodies to calpain 3 and protein expression in muscle from patients with limb-girdle muscular dystrophy type $2 \mathrm{~A}$. American Journal of Pathology, 153: 1169-1179.

41. Vainzof M, Anderson LVB, Moreira ES, Paula F, Pavanello RCM, Passos-Bueno MR \& Zatz M (2000). Calpain 3: Characterization of the primary defect in LGMD2A and analysis of its secondary effect in other LGMDs. Neurology, 54: A436 (Abstract).

42. Vainzof M, Moreira ES, Passos-Bueno MR et al. (2002). The effect of telethonin deficiency in LGMD-2G and its expression in other forms of muscular dystrophies and congenital myopathies. Biochimica et Biophysica Acta - Genetic Basis of Diseases, 1588: 33-40.

43. Anderson LV, Harrison RM, Pogue R et al. (2000). Secondary reduction in calpain 3 expression in patients with limb girdle muscular dystrophy type 2B and Miyoshi myopathy (primary dysferlinopathies). Neuromuscular Disorders, 10: 553-559.

44. Vainzof M, Pavanello RCM, Anderson LVB, Moreira ES, PassosBueno MR \& Zatz M (2001). Dysferlin analysis in autosomal recessive limb-girdle muscular dystrophies (AR-LGMD). Journal of Molecular Neuroscience, 17: 71-80

45. Bushby K \& Beckmann J (2003). The 105th ENMC workshop pathogenesis in the non-sarcoglycan limb-girdle muscular dystrophies. Neuromuscular Disorders, 13: 80-90.

46. Anderson LV, Davison K, Moss JA et al. (1999). Dysferlin is a plasma membrane protein and is expressed early in human development. Human Molecular Genetics, 8: 855-861.

47. Ho M, Gallardo E, McKenna-Yasek D, De Luna N, Illa I \& Brown Jr $\mathrm{RH}$ (2002). A novel, blood-based diagnostic assay for limb girdle muscular dystrophy 2B and Miyoshi myopathy. Annals of Neurology, 51: 129-133.

48. Matsuda C, Hayashi YK, Ogawa M, Aoki M, Murayama K, Nishino I, Nonaka I, Arahata K \& Brown Jr RH (2001). The sarcolemmal proteins dysferlin and caveolin-3 interact in skeletal muscle. Human Molecular Genetics, 10: 1761-1766.

49. Gregorio CC, Granzier H, Sorimachi H \& Labeit S (1999). Muscle assembly: a titanic achievement? Current Opinion in Cell Biology, 11: 18-25.
50. Wallgren-Pettersson C \& Laing NG (2001). Report of the 83rd ENMC International Workshop: 4th Workshop on Nemaline Myopathy. Neuromuscular Disorders, 11: 589-595.

51. Gurgel-Giannetti J, Reed UC, Bang ML et al. (2001). Nebulin expression in Nemaline myopathy. Neuromuscular Disorders, 11: 154-162.

52. Vainzof M (2001). Miopatias congênitas. In: Carakushansky G (Editor), Doenças Genéticas em Pediatria. Guanabara Koogan S/A, Rio de Janeiro, RJ, Brazil.

53. Bione S, Maestrini E, Rivella S, Mancini M, Regis S, Romeo G \& Toniolo D (1994). Identification of a novel X-linked gene responsible for Emery-Dreifuss muscular dystrophy. Nature Genetics, 8: 323327.

54. Bonne G, Di Barletta MR, Varnous S et al. (1999). Mutations in the gene encoding lamin $\mathrm{A} / \mathrm{C}$ cause autosomal dominant Emery-Dreifuss muscular dystrophy. Nature Genetics, 21: 285-288.

55. Lefebvre S, Burglen L, Reboullet S et al. (1995). Identification and characterization of a spinal muscular atrophy-determining gene. Cell, 80: 155-165.

56. Young PJ, Le TT, Dunckley M, Nguyen TM, Burghes AH \& Morris GE (2001). Nuclear gems and Cajal (coiled) bodies in fetal tissues: nucleolar distribution of the spinal muscular atrophy protein, SMN. Experimental Cell Research, 265: 252-261.

57. Hillaire D, Leclerc A, Faure S et al. (1994). Localization of merosinnegative congenital muscular dystrophy to chromosome 6q2 by homozygosity mapping. Human Molecular Genetics, 3: 1657-1661.

58. Vainzof M, Reed UC, Schwartzman JS, Pavanello RCM, PassosBueno MR \& Zatz M (1995). Deficiency of merosin (laminin M or $\alpha 2$ ) in congenital muscular dystrophy associated with cerebral white matter alterations. Neuropediatrics, 26: 293-297.

59. Sewry CA, Naom I, D'Alessandro M, Sorokin L, Bruno S, Wilson LA, Dubowitz $V$ \& Muntoni F (1997). Variable clinical phenotype in merosin-deficient congenital muscular dystrophy associated with differential immunolabelling of two fragments of the laminin alpha 2 chain. Neuromuscular Disorders, 7: 169-175.

60. Naom I, D'Alessandro M, Sewry CA, Jardine P, Ferlini A, Moss T, Dubowitz V \& Muntoni $F$ (2000). Mutations in the laminin alpha2chain gene in two children with early-onset muscular dystrophy. Brain, 123: 31-41.

61. Muntoni F, Brockington M, Blake DJ, Torelli S, Cegrí CA \& Brown SC (2002). Disorders of glycosylation: an emerging group of muscular dystrophies. Neuromuscular Disorders, 12: 718.

62. Pepe G, Bertini E, Ronaldo P et al. (2002). Bethlem myopathy (BETHLEM) and Ullrich scleroatonic muscular dystrophy: 100th ENMC International Workshop, November 23-24, 2001, Naarden, The Netherlands. Neuromuscular Disorders, 12: 984-993. 